\title{
Developing Talented Soccer Players: An Analysis of Socio-Spatial Factors as Possible Key Constraints
}

\author{
by \\ Jaime Serra-Olivares ${ }^{1}$, Juan C. Pastor-Vicedo², Sixto González-Víllora ${ }^{3}$, \\ Israel Teoldo da Costa ${ }^{4}$
}

\begin{abstract}
Most studies on the identification and development of soccer talent have been one-dimensional in nature. Although some multi-dimensional analyses have been conducted, few research studies have assessed in any depth the socio-spatial factors influencing talent development. The aim of this particular study was to analyse variations in the international representation of clubs $(n=821)$ and countries $(n=59)$ in the development of players who took part in the 2014 FIFA Soccer World Cup. Clubs and countries were ranked and divided into quartiles according to the number of players developed between the ages of 15 and 21 (clubs and countries that developed players for at least three years between these ages) and the number of official league matches played by these players up to the age of 23. Significant variations were observed between clubs in terms of the number of developed players who took part in the World Cup and the number of official league matches played by these players up to the age of $23(p<.05)$, and also between countries $(p<.05)$. The findings reveal the need to carry out more in-depth studies into the type of training and competition engaged in by elite players in the period of development between the ages of 15 and 21. It may be the case that these factors are potentially decisive socio-spatial constraints in the development of soccer talent.
\end{abstract}

Key words: social factors, talent development, training, ecological dynamics.

\section{Introduction}

It is generally agreed in the literature that athletes need to invest several years in training and competition in order to achieve the elite level in sport (Ward et al., 2004, 2007). Some researchers assume that environmental factors play an important role in individual differences between athletes (Starkes and Ericsson, 2003). These factors have contributed to two of the main explanatory theories of elite performance in sport, namely the rule of 10.000 hours or 10 years of practice (Simon and Chase, 1973) and the law of exponential practice (Newell and Rosenbloom, 1981). However, in terms of the interaction between performance-influencing factors (i.e., biological, psychological and social domains), it is not yet clear what form this investment in development should take in order to reach the elite level (Abbot and Collins, 2007; Ericsson et al., 1993; Matos et al., 2011).

In terms of ecological dynamics, it has been argued that sports performance involves an intentional adaptation to the constraints imposed by a specific context in performing a specific task (Araújo and Davids, 2009). In this respect, athletes and their context represent two dynamic subsystems that are connected and which interact on a mechanical and informational level (Almeida et al., 2013; Serra-Olivares et al., 2015). Hence

1 - Department of Physical Education Pedagogy. Faculty of Education. Catholic University of Temuco (Chile).

2 - Department of Physical Education. Teacher Training Faculty of Toledo. University of Castilla-La Mancha.

3 - Department of Physical Education. Teacher Training Faculty of Cuenca. University of Castilla-La Mancha

4 - Núcleo de Pesquisa e Estudos em Futebol, Universidade Federal de Viçosa, Viçosa, MG, Brasil. 
there is a need to understand, as part of the quest for sporting excellence, the link between the individuals and these factors, which are biological, psychological and social in nature, in the performance-development phase.

Authors such as Seifert et al. (2013) hold that elite athletes, much like complex dynamic systems immersed in processes of degeneration (contexts that aid the development of the ability to achieve similar results in different situations), adapt their behaviour and are able to coordinate degrees of freedom of movement owing to these and other properties: "multi-stability", "meta-stability" and "variability". What this means is that these athletes are able to vary their motor behaviour on a structural level, without their functions being undermined, through procedures that link information and movement (Whitacre and Bender, 2010), all of which provides sufficient evidence of the adaptive and functional role of movement in satisfying the demands of a specific task, context and environment. In this respect, Seifert et al. (2013) state that the presence of degeneration processes in biological systems increases their complexity and ability to withstand potentially disruptive agents. This enables the attainment of optimal levels of "pluripotency", a property that enables the continuous functional ability to link sport behaviours (game behaviours) in changing performance contexts.

With regard to the development of the expert athletes and also in relation with the ecological dynamics perspective, it has been suggested that there exist specific critical periods of development and specific influential factors (biological, psychological and social) that act as key constraints prior to the athlete achieving elite performance. In terms of the relationship between the periods of development and the type of practice engaged in (mainly context- and taskrelated constraints), for example, it has been recommended that talented athletes make a gradual transition from a general type of game practice at an early age to a more specialised type of practice in a specific sport in later stages. From the perspective of skills acquisition, a diversified development of the young athlete approach leads to improved specific athletic performance. However, the researchers caution that, once the general cognitive or physical adaptations have been made through the participation in various sporting activities in childhood, training should be more specific. Some of the foundations are due to the fact that elite athletes like practicing various sports during childhood rather than specializing in a single sport, are involved in a greater amount of free play than deliberate practice, while during their adulthood elite athletes are more involved in deliberate practice and less in free play (Abernethy et al., 2002; Côté and Fraser-Thomas, 2007; Ford et al., 2009). Thus, specific practices highlight athletes as complex systems which adapt their behaviours and coordinating movement's degrees of freedom in a more contextualized practice, under degeneracy processes (Whitacre and Bender, 2010).

Some authors have even set out chronological periods in which athletes should be introduced to a specific type of practice. For example, Côté et al. (2007) proposed a performance-oriented trajectory comprising three different stages: the sampling years (6 to 12$)$, the specialising years (13 to 15 ) and the investment years (over 16), while highlighting the importance of appropriate physical development patterns and psychosocial influences. As a result, it is expected that individuals can vary their actions in a functional way in specific performance situations, providing evidence for flexible behaviours within different configurations of ecological constraints (Seifert et al., 2013). The above are all reasons underpinning the study of the impact of performance-influencing factors, particularly psychosocial ones, on the investment years from the age of 15 until reaching the elite level (Baker et al., 2003).

In specific terms and in terms of the influence of the social domain on the development of sports performance, research has been carried out in order to understand the socio-spatial factors determining the production of sports talent (Maguire, 1995; Morgan and Giacobbi, 2006; Phillips et al., 2010). It has been argued that sport comprises varying spatial dimensions, among them the distribution of players and clubs, their organisations and competitions, the distribution of memberships and associations, the effects of socio-spatial processes, the geopolitical impact, nationalities and the geography of the economic impact of professional sport (McGowin, 2010).

These dimensions affect, for example, the 
political/economic processes involved in the identification and development of soccer players (Poli et al., 2014). A number of studies have pursued this line of research with the aim of investigating socio-spatial factors crucial to the development of sports talent. Some authors have researched the location of sports facilities and their accessibility for athletes (Burke and Woolcock, 2009, 2012), the use of sport as a means of strengthening local identification (Harris and Wise, 2011), the inconsistency within talent identification processes (Wiseman et al., 2014) or the influence of the Human Development Index on the possibilities of young soccer players achieving the elite level in professional soccer in Brazil, where, at a certain stage of their sports development, large numbers of talented young players leave their home towns for the cities where clubs are based (Teoldo et al., 2013).

Other studies have analysed the influence of the birthplace of elite athletes (Abernethy and Farrow, 2005; Côté et al., 2006; Curtis and Birch, 1987) and the birthdates of high-performance players (Gutiérrez-Díaz et al., 2010; Sallaoui et al., 2014). However, the main drawback with most of these studies is that they do not take into account the places in which these athletes underwent most of their development (socio-spatial constraints) and do not bear in mind the high level of residential mobility among athletes and the influence this has on training. In this respect, most studies on the identification and development of sports talent have been one-dimensional (Abbott et al., 2002; Wiseman et al., 2014).

Although some studies have approached talent development from a more revealing multidimensional perspective (Davids et al., 2013; Nieuwenhuis et al., 2002; Reilly et al., 2000), few have taken socio-spatial factors into consideration as potential constraints influencing the development of sports talent (Woolcock and Burke, 2013). Moreover, no study has yet analysed these socio-spatial factors as potential key constraints from the perspective of ecological dynamics and motor learning (Phillips et al., 2010).

In contrast, recent studies underline the importance of socio-spatial factors in the development of sports talent, with special attention being given to the relationship between birthplace and the place of talent development ahead of other variables such as birthdate (MacDonald et al., 2009; Woolcock and Burke, 2013). A number of studies carried out in lowpopulation areas have revealed the phenomenon of over-representation in sport, such as in the National Hockey League in Canada (Curtis and Birch, 1987) or the soccer league in the USA (Côté et al., 2006; MacDonald et al., 2009) and Australian athletics (Abernethy and Farrow 2005). This finding reveals the impact of the training/competition context on talent development, such as constraints inherent in socio-spatial factors (Christensen et al., 2011; MacDonald et al., 2009; Pazo-Haro et al., 2012). A question arises: is the place where sports talent is developed really an influential factor? Is there a period of development in which socio-spatial constraints influence talent development?

In attempting to tackle these questions in the sport of soccer, this study aimed to analyse the possible existence of variations in the international representation of soccer clubs and countries in the development of the players who took part in the 2014 FIFA Soccer World Cup. The main objective was to assess the variations in the number of players developed by these clubs ("club players") and countries in the 15-21 age group and in the number of official league matches played by these players up to the age of 23 in these clubs ("training clubs") and countries. The baseline hypothesis was that there would be variations in the international representation of clubs and countries, which would point to the existence of a critical development period in which special attention should be paid to sociospatial factors as potential key constraints in the development of sports performance.

\section{Material and Methods}

\section{Participants}

Data was collated on 821 soccer clubs and 59 countries that contributed to the development of the players who took part in the 2014 FIFA Soccer World Cup. In specific terms, the number of participating players developed per country and per club (728) was recorded, as was the number of official league matches played by these players up to the age of $23(68,151)$. These criteria for selecting the sample, based on the aforementioned age limit, were chosen in line with FIFA regulations on training compensation 
and UEFA's definition of "training clubs" and "club players" (FIFA REGULATIONS 2014; Poli et al., 2014; UEFA Club Licensing and Financial Fair Play Regulations Edition, 2010). A "training club" was regarded as any club that trained a player who took part in the 2014 FIFA Soccer World Cup for at least three seasons between the ages of 15 and 21. Similarly, a "club player" was regarded as any participant in the 2014 FIFA Soccer World Cup employed (on a national association contract) by a "training club" for at least three seasons between the ages of 15 and 21. This research study complied with the Declaration of Helsinki's requirements with regard to the code of ethics of research involving human subjects, and was approved by the ethics committees of the Catholic University of Temuco, University of Castilla-La Mancha and Federal University of Viçosa.

\section{Procedures}

Data was obtained from the International

Centre for Sports Studies' (CIES) Soccer Observatory (Poli et al., 2014), checked by FIFA and UEFA associations. The 59 countries and 821 clubs that contributed to the development of the players who took part in the 2014 FIFA Soccer World Cup were ranked and the details of these clubs and countries recorded. As part of this process, the number of "club players" developed by each "training club" and country between the ages of 15 and 21 was taken into consideration. The countries were then divided, on the basis of their ranking, into four quartiles as follows: first quartile: from the top-ranked country to the 14th; second quartile: from the 15th to the 30th; third quartile: from the 31st to the 45th; and the fourth quartile: from the 46th to the 59th. The same process was applied to data on the 821 "training clubs": first quartile: from the top-ranked "training club" to the 205th; second quartile: from the 206th to the 410th; third quartile: from the 411th to the 616th; and the fourth quartile: from the 617th to the 821st. These quartiles were created to enable analysis of the variations between countries and also between "training clubs" with regard to the number of "club players" developed and the number of official league matches played by these players up to the age of 23 .

\section{Data analysis}

The normality and homogeneity of the variances in the variables analysed were respectively calculated by means of the Kolmogorov-Smirnov and Levene's tests. The results of this analysis showed that the variables studied were normal. Parametric tests were conducted as a result. A descriptive analysis (mean and typical deviation) was carried out with a view to obtaining more exact information on the research context. The single-factor ANOVA test was used with Bonferroni multiple-comparison corrections to analyse the information in greater depth. The purpose of performing this inferential analysis was to identify possible variations between the quartiles in which the countries and "training clubs" (independent variables) were ranked, with regard to the number of "club players" and the number of official league matches played by these players up to the age of 23 (dependent variables). SPSS Statistics 19.0 was used, with a confidence interval of 95 percent being set throughout the process.

\section{Results}

\section{International representation by countries}

With regard to the number of developed "club players" who took part in the 2014 FIFA Soccer World Cup and the number of official league matches played by these "club players" up to the age of 23 , analysis by countries revealed significant variations between the four quartiles studied. The variations were only non-significant in comparisons between countries in the third and fourth quartiles (Table 1).

\section{International representation by "training clubs"}

In relation to the number of developed "club players" who took part in the 2014 FIFA Soccer World Cup and the number of official league matches played by these "club players" up to the age of 23 , analysis by "training clubs" revealed significant variations between the four quartiles studied. In comparisons between clubs in terms of the number of developed "club players", the variations were only non-significant in the third and fourth quartiles, and in comparisons between clubs in terms of the number of official league matches played by "club players" up to the age of 23 , the variations were only non-significant in the second and third quartiles (Table 2).

\section{Discussion}

The aim of this study was to analyse the 
variations in the international representation of clubs and countries in the development of players who took part in the 2014 FIFA Soccer World Cup. The results of the study showed that there were significant variations in this representation, both at a club and country level. These findings point to the quality of practices engaged in by certain clubs in particular, and to the possible existence of a development stage in which sociospatial factors play a decisive role in the development of sports performance. This latter idea has previously been put forward by other authors (Ericsson et al., 1993; Ford et al., 2009; Ward et al., 2004, 2007), although further studies, particularly those of a longitudinal nature, are needed to confirm this hypothesis.
The results of this study are consistent with others in which it was stated that socio-spatial factors played a key role in the development (MacDonald et al., 2009; Teoldo et al., 2013; Woolcock and Burke, 2013) and identification of sports performance (Wiseman et al., 2014). Consequently, variations were observed in the number of "training clubs" and developed "club players" who took part in the 2014 FIFA Soccer World Cup and in the number of official league matches played by these players up to the age of 23.

Table 1

Variations in the number of "club players" (FIFA 2014) developed per country and official league matches played up to the age of 23.

\begin{tabular}{|c|c|c|c|c|}
\hline \multirow{4}{*}{$\begin{array}{l}\text { Dependent variable } \\
\text { Club players } \\
\text { developed } \\
\text { per country }\end{array}$} & \multicolumn{2}{|c|}{ (I) Countries (I) Countries } & \multirow{2}{*}{$\frac{\text { Mean variation }(\mathrm{I}-\mathrm{I})}{11.42^{*}}$} & \multirow{2}{*}{$\begin{array}{c}\underline{p} \\
.000\end{array}$} \\
\hline & 1st quartile & 2nd quartile & & \\
\hline & & 3rd quartile & $26.57^{*}$ & .000 \\
\hline & & 4th quartile & $30.00^{*}$ & .000 \\
\hline \multirow{22}{*}{$\begin{array}{l}\text { U-23 matches } \\
\text { played }\end{array}$} & 2nd quartile & 1st quartile & $-11.42^{*}$ & .000 \\
\hline & & 3rd quartile & $15.14^{*}$ & .000 \\
\hline & & 4th quartile & $18.57^{*}$ & .000 \\
\hline & 3rd quartile & 1st quartile & $-26.57^{*}$ & .000 \\
\hline & & 2nd quartile & $-15.14^{*}$ & .000 \\
\hline & & 4th quartile & 3.42 & .635 \\
\hline & 4th quartile & 1st quartile & $-30.00^{*}$ & .000 \\
\hline & & 2nd quartile & $-18.57^{*}$ & .000 \\
\hline & & 3rd quartile & -3.42 & .635 \\
\hline & 1st quartile & 2nd quartile & $2021^{*}$ & .000 \\
\hline & & 3rd quartile & $3062^{*}$ & .000 \\
\hline & & 4th quartile & $3271^{*}$ & .000 \\
\hline & 2nd quartile & 1st quartile & $-2021^{*}$ & .000 \\
\hline & & 3rd quartile & 1040 & .055 \\
\hline & & 4th quartile & $1249^{*}$ & .008 \\
\hline & 3rd quartile & 1st quartile & $-3062^{*}$ & .000 \\
\hline & & 2nd quartile & -1040 & .055 \\
\hline & & 4th quartile & 209 & 1.000 \\
\hline & 4th quartile & 1st quartile & $-3271^{*}$ & .000 \\
\hline & & 2nd quartile & $-1249^{*}$ & .008 \\
\hline & & 3rd quartile & -209 & 1.000 \\
\hline & & 3rd quartile & -3.80 & 1.000 \\
\hline
\end{tabular}




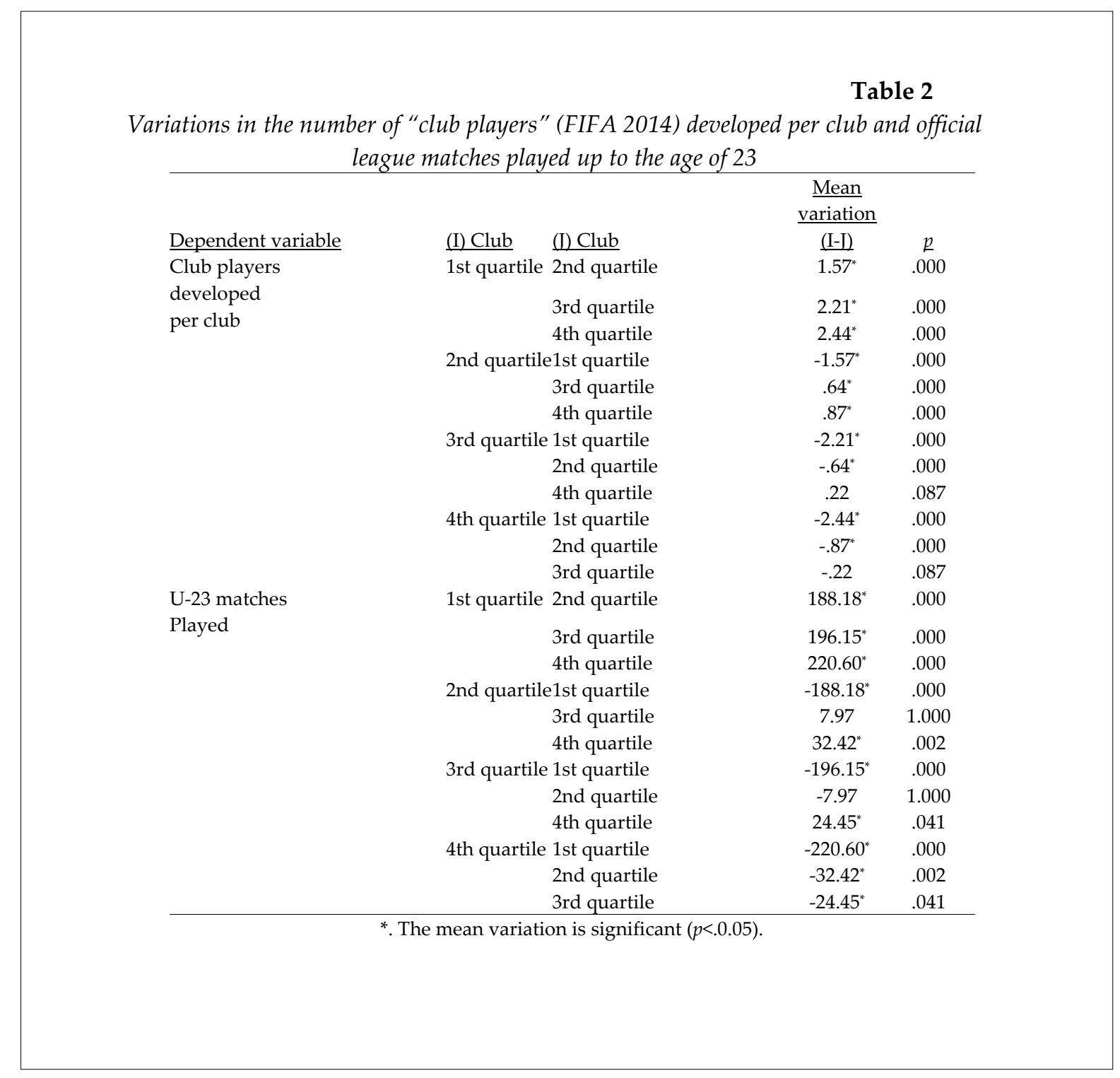

This phenomenon of "overrepresentation" (which in this case is observed in the clubs that developed players who took part in the 2014 FIFA Soccer World Cup) has also been noted in other contexts ((Abernethy and Farrow, 2005; Côté et al., 2006; Curtis and Birch, 1987; MacDonald et al., 2009). It has been explained by the differing opportunities open to athletes in large and small cities and their influence on the development of performance (MacDonald et al., 2009).

In this respect, one possible explanation of the phenomenon of the international "overrepresentation" of certain clubs and countries studied in this research paper is the mobility of professional soccer players in recent years. In a recent demographic study, Poli et al. (2014) observed that the percentage of expatriate players (players born in one country, but choosing to play for the national team of another country in which their current club is based, and players moving abroad to play for different reasons) reached a record level in the 2014 season (36.8\%). These authors also noted that the proportion of players moving abroad during their sporting career had never been as high as it was that year (49.3\%). In this respect, they pointed out that the increase in the international mobility of soccer players was linked to a fall in the percentage of "club players". Despite the regulations introduced in many countries and in UEFA club competitions, the presence of "club players" fell to an all-time low in the 2014 season (21.2\%).

Another possible explanation of the 
phenomenon is the social and psychological influence on talent identification and development (i.e. parents, coaches, peers, etc.), which could affect future talent development (Wiseman et al., 2014) as other key elements (Gutiérrez-Díaz et al., 2010). It is necessary to highlight that talent identification and development processes are dynamic and they are interrelated. It is thus necessary to place greater emphasis on player's adaptability and capability to be developed in a specific sport context, taking into account the psychological factors that underpin these practices (Abbot and Collins, 2007).

Existing data and this study's findings on the international representation of "club players" and "training clubs" point to the need to focus on the type of practice performed as part of the development of talented soccer players, regardless of their geographical location (Côté and Fraser-Thomas, 2007; MacDonald et al., 2009). It would appear that "club players" developed between the ages of 15 and 23 by the "training clubs" analysed in this study had more practice opportunities than other players belonging to other clubs (training and non-training clubs). The findings of this study show that the phenomenon of "over-representation" is influenced more by the type of practice performed by these players than by the amount of practice opportunities.

The influence of socio-spatial factors as key elements in the development of sports performance has been previously studied (Côté et al., 2006; Pazo-Haro et al., 2012; Teoldo et al., 2013), with the relationship between learning conditions and the level of performance being emphasised (Araújo and Davids, 2009; Renshaw et al., 2010). In specific terms and in relation to social factors influencing sports, authors such as Pazo-Haro et al. (2012) highlighted the influence of the social context and the professional team on the development of players in the Spanish national team, while other authors such as Christensen et al. (2011), studying the process of developing talented U-18 soccer players from the perspective of learning communities, showed the importance of an inclusive approach in training sessions. The main objective of this approach is to contribute to the development of the psychosocial skills of personal responsibility and strategic planning during the player's transition to an expert/professional level (Matos et al., 2011; Morgan and Giacobbi, 2006). With regard to spatial factors, in spite of the geographical study of sport (Woolcock and Burke, 2013), recommendations made in the last few years have focused mainly on sports instruction and teaching and the type of practice to be performed by talented athletes (Baker and Horton, 2004; Côté and Fraser-Thomas, 2008; Ward et al., 2004, 2007), although to some extent they have adopted a reductionist vision of performance development (Almeida et al., 2013).

Among recommendations on the type of practice to be performed by athletes in attempting to achieve high levels of performance, a special mention should be made of an approach to motor development based on constraints and non-linear instruction (Phillips et al., 2010; Renshaw et al., 2010). This is an innovative approach to understanding sports talent development from a multi-disciplinary perspective founded on ecological dynamics and motor learning (Davids et al., 2013; Seifert et al., 2013). It is a line of research that views the developing individual as a complex non-linear neurobiological system, which enables the process of acquiring complex motor skills to be viewed and understood in an alternative manner to traditional models of performance development (Serra-Olivares et al., 2015). This construct underscores the indivisible relationship between the individual's genetic factors and the context around them. It is only when the interaction between genetic factors and context constraints is favourable that performance results can be observed (Ward et al., 2004, 2007). This would explain the findings of this study mainly in terms of the international representation of the "training clubs" that contributed to the sports development, between the ages of 15 and 23, of the players who took part in the 2014 FIFA Soccer World Cup.

In terms of the part played by ecological dynamics and motor learning in the development of sports talent, it is argued that an understanding of the following is needed to bring about a favourable interaction between genetic factors and the context: the athletes' level of performance in a specific task, the intentions/goals that athletes are required to achieve and the main constraints (of the individual, the task and the context) that may be dealt with during the learning process. It 
is suggested that sports talent development programmes should allow the individual to experience information processes integral to sports performance contexts. These programmes should give learners the opportunity to explore and create opportunities for action, as a means of developing "multi-stability", "meta-stability" and "variability" properties, instead of restricting them by having them receive information passively. In light of the above, there is a need to focus on the relationship between the individual and the context in studies that take talent and performance development in sport and in soccer in particular as their subject. In this respect, this study's findings point to the possibility that sociospatial factors have a decisive role to play in this relationship.

It may be concluded, therefore, that the relationship between the athlete and the context was a key constraint on performance development during the period of development of players who took part in the 2014 FIFA Soccer World Cup, specifically between the ages of 15 and 23. This phenomenon can be termed "sociospatial-talent", which encompasses the "social" and "spatial" factors as well as their influence on the development of sports talent. New studies are nevertheless needed to confirm this theory, particularly studies that examine the socio-spatial relationship between athletes and the context in the period between the ages of 15 and 23, which corresponds to the period of investment in the development of elite athletes (Côté et al., 2007). It would be worthwhile to conduct similar studies on other soccer championships, other sports and with other participant samples.

\section{References}

Abernethy B, Côté J, Baker J. Expert decision making in team sport. Report to the Australian Sports Commission. Brisbane: University of Queensland; 2002

Abernethy AB, Farrow D. Contextual factors influencing the development of expertise in Australian athletes. In T. Morris, PC. Terry, S. Gordon, S. Hanrahan, L. Ievleva, G. Kolt and P. Tremayne (Eds.), Promoting Health and Performance for Life. Sydney: International Society of Sport Psychology, 15-19; 2005

Almeida CA, Ferreira AP, Volossovitch A. Offensive sequences in youth soccer: effects of experience and small-sided games. J Hum Kinet, 2013; 36: 97-106

Abbot A, Collins D. Eliminating the dichotomy between theory and practice in talent identification and development: considering the role of psychology. J Sport Sci, 2007; 5: 395-408

Araújo D, Davids K. Ecological approaches to cognition and action in sport and exercise: ask not only what you do, but where you do it. Int J Sport Pychol, 2009; 40: 5-37

Baker J, Cobley S. Does practice make perfect? The role of training in developing the expert athlete. In D. Farrow, J. Baker and C. McMahon (Eds.), Developing sport expertise. London: Taylor \& Francis, 29-42; 2008

Baker J, Côte J. Shifting training requirements during athlete development: The relationship among deliberate practice, deliberate play and other sport involvement in the acquisition of sport expertise. In D. Hackfort and G. Tenebaum (Eds.), Essential Processes for Attaining Peak Performance. Germany: Meyer and Meyer, 93-110; 2006

Baker J, Horton S. A review of primary and secondary influences on sport expertise. High Ability Studies, 2004; 15: 211-28

Burke M, Woolcock G. Getting to the game: travel to sports stadia in the era of transit-oriented development, Sport in Society: Cultures, Commerce, Media, Politics, 2009; 12: 890-909

Burke M, Woolcock G. The impacts of transport accessibility and remoteness on Australian Football League (AFL) talent production: Findings from the 'Talent Tracker' project. 35th Australasian Transport Research Forum Proceedings. Editor: Brett Hughes, Ian Petkoff . Publisher: WA Department of 
Transport; 2012

Côte J, Hay J. Children's involvement in sport: A developmental perspective. In J. M. Silva and D. Steven (Eds.), Psychological Foundations of Sport. Boston: Merrill, 484-502; 2012

Côté J, Macdonald DJ, Baker J, Abernethy B. When "where” is more important than "when”: birthplace and birthdate effects on the achievement of sporting expertise. J Sport Sci, 2006; 24: 1065-73

Côte J, Fraser-Thomas J. Play, practice, and athlete development. In D. Farrow, J. Baker and C. McMahon (Eds.), Developing sport expertise. London: Taylor \& Francis, 17-28; 2008

Christensen MK, Laursen DN, Sørensen JK. Situated learning in youth elite football: a Danish case study among talented male under-18 football players. Phys Educ Peda, 2011; 16: 163-178

Curtis J, Birch J. Size of community of origin and recruitment to professional and Olympic hockey in North America. Sociol Sport J, 1987; 4: 229-44

Davids K, Araújo D, Vilar P, Renshaw I, Pinder R. An ecological dynamics approach to skill acquisition: implications for development of talent in sport. Talent Development $\mathcal{E}$ Excellence, 2013; 5: 21-34

Ericsson KA, Krampe R, Tesch-Römer C. The role of deliberate practice in the acquisition of expert performance. Phychological Review, 1993; 100: 363-406

FIFA Regulations. On the status and transfer of players, 2014 . Available at: http://www.fifa.com/aboutfifa/officialdocuments/index.html; accessed on 01.01.2015

Ford PR, Ward, Hodges NJ, Williams AM. The role of deliberate practice and play in career progression in sport: the early engagement hypothesis. High Ability Studies, 2009; 20: 65-75

Gutiérrez-Díaz D, Pastor-Vicedo JC, González-Víllora S, Contreras-Jordán OR. The relative age effect in youth soccer players training. Journal of Sports Science and Medicine, 2010; 9: 190-198

Harris J, Wise N. Geographies of scale in international Rugby Union. Geographical Research, 2011; 49: 375-83

Maguire J. Common ground? Links between sports history, sports geography, and the sociology of sport. Sporting Traditions: The Journal of the Australian Society for Sports History, 1995; 12: 3-25

Matos DS, Cruz JFA, Almeida LS. Excellence in sport: Towards an understanding of the psychological "architecture" of elite athletes. Motricidade, 2011; 7: 27-41

Mcgowin D. Sports, geography of. In Warf B. (Ed.), Encyclopedia of geography. Sage: Thousand Oaks, CA; 2010

Macdonald DJ, Cheung M, Côté J, Abernethy B. Place but not date of birth influences the development and emergence of athletic talent in American football. J Apll Sport Psycholl, 2009; 21: 80-90

Morgan T, Giacobbi P. Toward two grounded theories of the talent development and social support process of highly successful collegiate athletes. The Sport Psychologist, 2006; 20: 295-313

Newell A, Rosenbloom PS. Mechanisms of skill acquisition and the law of practice. In JR Anderson (Ed.), Cognitive skills and their acquisition. Hillsdale, NJ: Erlbaum, 1-55; 1981

Pazo-Haro CI, Sáenz-López P, Fradua-Uriondo L. Influence of sport context on training elite soccer players. Revista de Psicología del Deporte, 2012; 21: 291-299

Poli R, Besson R, Ravenel L. Demographic study, 2014. Available at: http://www.footballobservatory.com/?lang=en; accessed on 02.01.2015

Phillips E, Davids K, Renshaw I, Portus, M. Expert performance in sport and the dynamics of talent development. Sports Med, 2010; 40: 271-283

Renshaw I, Chow JY, Davids K, Hammond JA. Constraints-led perspective to understanding skill acquisition and game play: a basis for integration of motor learning theory and physical education praxis? Phys Educ Peda, 2010; 15: 117-137

Sallaoui R, Chamari K, Chtara M, Manai Y, Ghrairi M, Belhaouz M, Baroon A. The relative age effect in the 2013 FIFA U-17 Soccer World Cup competition. American Journal of Sports Science, 2014; 2: 35-40 
Seifert L, Button C, Davids K. Key properties of expert movement systems in sport. Sports Med, 2013; 43(3): $167-178$

Serra-Olivares J, González-Víllora S, García-López LM, Araújo D. Game-centred approaches' pedagogical principles: Exploring task constraints in youth soccer. J Hum Kinet, 2015; 46; 251-261

Simon HA, Chase WG. Skill in chess. American Scientist, 1973; 61: 394-403

Starkes JL, Ericsson KA. Expert performance in sports: Advances in research on sport expertise. Champaign IL; Human Kinetics; 2003

Teoldo I, Cardoso F, Garganta J. Could the human development index and birth-date of the players influence the climbing up to higher performance in soccer? Motriz, 2013; 19: 34-45

UEFA Club Licensing and Financial Fair Play Regulations Edition (2010). Available at: http://www.uefa.com/MultimediaFiles/Download/uefaorg/Clublicensing/01/50/09/12/1500912_DOWN LOAD.pdf

Ward P, Hodges NJ, Williams AM, Starkes JL. Deliberate practice and expert performance: defining the path to excellence. In A. M. Williams y N. J. Hodges (Eds.), Skill Acquisition in Sport: Research, Theory and Practice. London: Routledge, 231-258; 2004

Ward P, Hodges NJ, Williams AM, Starkes JL. The road to excellence in soccer: A quasi-longitudinal approach to deliberate practice. High Ability Studies, 2007; 18: 119-153

Whitacre JM, Bender A. Degeneracy: a design principle for achieving robustness and evolvability. $J$ Theor Biol, 2010; 263: 143-53

Wiseman AC, Bracken N, Horton S, Weir PL. The difficulty of talent identification: Inconsistency among coaches through skill-based assessment of youth hockey players. Int Jou Spo Sci \& Co, 2014; 3: 447-455

Woolcock G, Burke M. Measuring spatial variations in sports talent development: The approach, methods and measures of 'talent tracker'. Australian Geographer, 2013; 44: 23-39

\section{Corresponding author:}

\section{Jaime Serra-Olivares}

Department of Physical Education Pedagogy. Faculty of Education.

Catholic University of Temuco (Chile). Rudecindo Ortega 02950, Temuco (Chile).

E-mail: jserra@uct.cl. 